\title{
The Janus Corner
}

\section{Cyanobacterial Toxins as Targets for Anticancer Therapy}

\author{
I.E.Cock ${ }^{\mathrm{ab} *}$ \\ ${ }^{a}$ Biomolecular and Physical Sciences, Nathan Campus, Griffith University, 170 Kessels Rd, Nathan, Brisbane, Queensland 4111, Australia. \\ ${ }^{b}$ Environmental Futures Centre, Nathan Campus, Griffith University, 170 Kessels Rd, Nathan, Brisbane, Queensland 4111, Australia.
}

The control and eradication of cyanobacterial blooms has long been a goal of environmental scientists and those involved with water quality control due to the range of toxins which can be produced by some cyanobacteria. Some of these toxins may produce irritating effects such as "swimmers rash" whilst other cyanobacterial species produce more serious toxins, some of which may be lethal in humans (eg saxotoxin produced by Anabaena spp. and microcystins produced by Microcystis spp.). ${ }^{[1]}$ However, the potential of toxins for therapeutic purposes is also well known. Indeed, drugs have often been described as toxins used at therapeutic doses and toxicity has been used as an indicator of medicinal potential in many previous drug discovery studies. Therefore, it is not entirely surprising that medicinally important properties linked to a cyanobacterial toxin have recently been demonstrated. It was recently reported that one cyanobacterial family (Symploca) secretes a toxin (largazole) with anti-tumor activity against colon, bone and breast cancer cells. ${ }^{[2]}$ In contrast, largazole, had little effect in normal cell lines. This group has also undertaken in vivo studies in mice induced to produce colorectal tumors, demonstrating the ability of largazole to slow tumor progression. Further studies have identified inhibition of ubiquitin activating enzyme (E1) as a probable mechanism for the anticancer activity of largazole. ${ }^{[3]}$ The example of largazole shows the potential of toxins in the treatment of disease states such as cancer. It also indicates the potential of a source of natural drugs that has been largely overlooked previously those from aquatic organisms.

\section{REFERENCES}

1. Ruebhart DR, Wickramasinghe W, Cock IE. Protective efficacy of the antioxidants vitamin E and Trolox against Microcystis aeruginosa and microcystin-LR in Artemia franciscana nauplii. J Toxicol Environ Health Part A 2009; 72 (24): 1567-1575.

2. Taori K, Paul VJ, Leusch J. Structure and activity of largazole, a potent antiproliferative agent from Floridian marine cyanobacterium Symploca sp. J Am Chem Soc 2008; 130: 1806-1807.

3. Ungermannova D, Parker SJ, Nasveschuk CG, Wang W, Quade B, Zhang G, Kuchta RD, Phillips AJ, Liu X. Largazole and its derivatives selectively inhibit ubiquitin activating enzyme (E1). Plos One 2012; 7(1): e29208. 